\title{
La Fiscalía y la protección del patrimonio cultural
}

Antonio Roma Valdés, Fiscalia de Santiago de Compostela

Generalmente se asocia al Ministerio Fiscal con el proceso penal, sin embargo su actuación excede de este límite aparente. En concreto, la actuación de la Fiscalia se ha mostrado activa en la protección del patrimonio cultural también fuera de ese ámbito siendo forzoso reconocer que, de todas las fiscalias españolas, las andaluzas han mostrado un enorme protagonismo. Una de las razones que han fomentado esta tendencia es la capacidad de los fiscales de fomentar una especialización en la persecución de determinadas formas de delincuencia. El artículo 20 de la Ley 50/1981 del Estatuto Orgánico del Ministerio Fiscal, en su redacción otorgada por la Ley 24/2007, establece que en la Fiscalía General del Estado existirá un fiscal contra los delitos relativos a la ordenación del territorio y la protección del patrimonio histórico, del medio ambiente e incendios forestales, con categoria de Fiscal de Sala, entre cuyas funciones está la coordinación de las fiscalias, unificando los criterios de actuación.

Las lineas fundamentales desarrolladas desde las fiscalias en la mejora de la protección del patrimonio cultural fuera del proceso penal se pueden resumir en los siguientes aspectos:

1. Seguimiento estadístico de la delincuencia. El primer ámbito de intervención de la Fiscalía se ha centrado en el seguimiento de los delitos sobre el patrimonio cultural que son objeto de procedimientos judiciales. No siempre esta labor se ha efectuado con el rigor que podría alcanzarse y una de las principales dificultades es el hecho de que las figuras penales que afectan al patrimonio cultural se encuentran dispersamente reguladas en el Código Penal (GARCÍA CALDERÓN, 1999). En el gráfico inferior se muestra la evolución numérica de delitos de daños al patrimonio cultural en los procedimientos judiciales de toda España.

Por otro lado, el número de sentencias por estos delitos (ver tabla de p. 76) no arroja unos datos particularmente elevados. La diferencia entre la amplitud del número de procedimientos judiciales con el volumen de sentencias se explica en el dato de que son muy pocos los supuestos en los que se ha identificado al autor.

2. Propuestas de reformas legislativas. Las memorias de la Fiscalía General del Estado han interesado de manera excepcional reformas legislativas tendentes a la necesaria mejora de la protección penal del patrimonio cultural. En este punto, la Memoria del Fiscal General del Estado presentada a las Cortes Generales el año 2006 propugnó una mejora del artículo 322 del Código Penal, que castiga la concesión de autorizaciones de demolición de edificios singularmente protegidos dada su confusa relación con otras autorizaciones urbanisticas ilegales penalmente sancionadas y su insuficiencia en la protección de edificios protegidos por figuras del planeamiento.

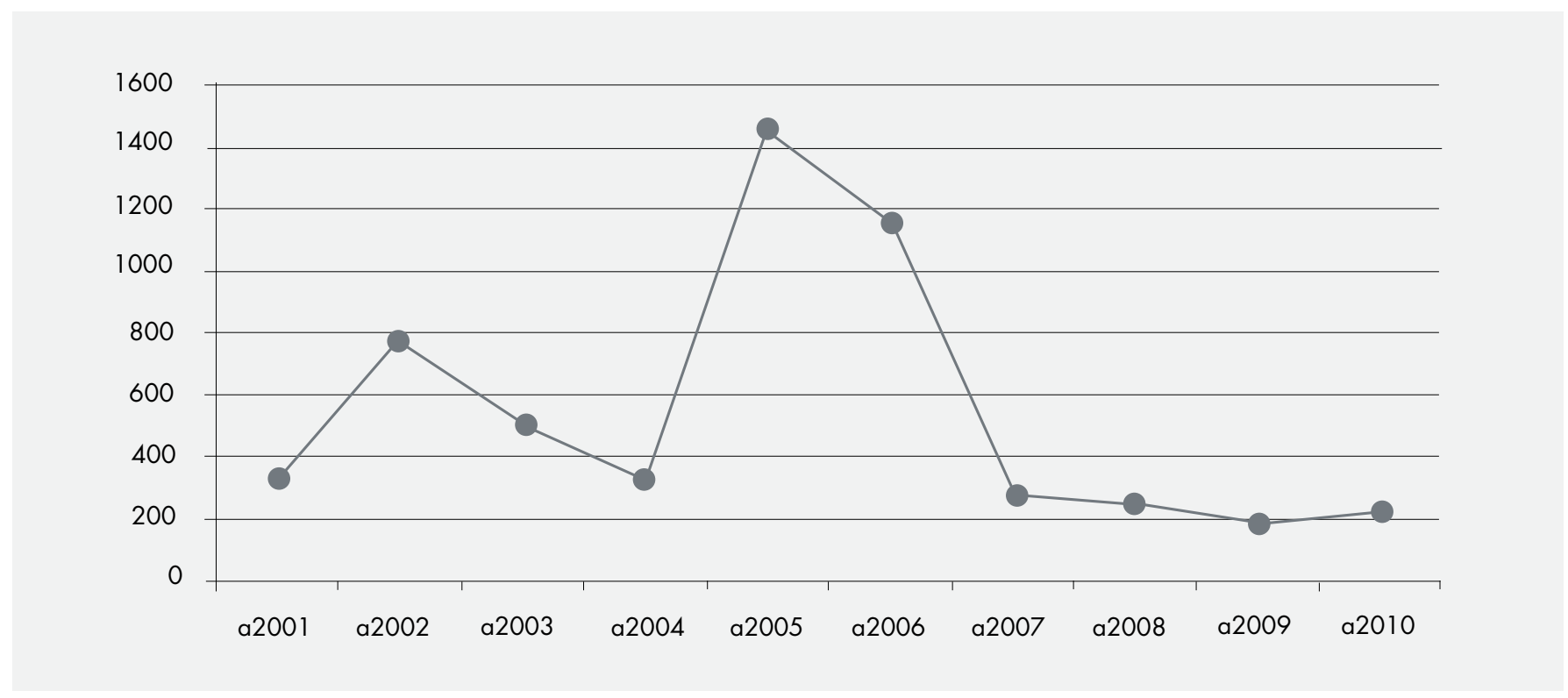

Evolución numérica de delitos de daños al patrimonio cultural en los procedimientos judiciales de toda España 
Año Sentencias condenatorias Sentencias absolutorias

\begin{tabular}{lll}
\hline 2009 & 13 & 3 \\
\hline 2010 & 10 & 16 \\
\hline
\end{tabular}

La diferencia entre la amplitud del número de procedimientos judiciales con el volumen de sentencias se explica en el dato de que son muy pocos los supuestos en los que se ha identificado al autor

Es mucho más prolija en su alcance la propuesta de reforma legislativa planteada por la Fiscalia de Andalucia y el Defensor del Pueblo Andaluz, manifestada a través de las conclusiones de la IV Jornada de trabajo de la Oficina del Defensor del Pueblo Andaluz y la Fiscalia del Tribunal Superior de Justicia de Andalucia: Los delitos sobre la ordenación del territorio; el patrimonio histórico y el medio ambiente, fechada en Sevilla en marzo de 2007, y con antecedente en otra reunión de 26 de enero de 2006. Se viene a proponer un articulado concreto que dotase de homogeneidad y actualidad al deficiente estado actual de legislación penal del patrimonio cultural.

Tampoco ha tenido recepción por parte del legislador las propuestas que el Consejo Fiscal planteó en relación con la modificación de la legislación de contrabando en su informe de 1 de junio de 2010. El delito de contrabando existe en los supuestos de exportación ilegal de bienes pertenecientes al patrimonio cultural. La reforma operada por la Ley Orgánica 6/2011, desoyendo la apreciación del Consejo Fiscal, ha dejado en nuestro ordenamiento jurídico una falta de armonía entre la legislación sustantiva de contrabando y el artículo 282 bis de la Ley de enjuiciamiento criminal, que faculta una herramienta de persecución de la criminalidad organizada para esta forma de delincuencia como es el nombramiento de agentes encubiertos. Como se aprecia, el interés de la Fiscalia en su conjunto no ha encontrado eco en la sensibilidad del legislador español.

3. Actuaciones de coordinación. Al margen de las anteriores iniciativas, merece indicarse que en otras ocasiones las fiscalias territoriales han iniciado acciones dirigidas a coordinar medidas de prevención de la delincuencia. Dentro de este conjunto pueden mencionarse dos supuestos, uno en Galicia y otro en Andalucia.

En Galicia, la Fiscalia Superior inició mediante un Decreto de 16 de julio de 2011 unas diligencias tendentes a otorgar protección al patrimonio en manos de la Iglesia católica, que en esta comunidad autónoma se encuentra en muchos casos en parroquias de difícil accesibilidad. Las actuaciones desarrolladas se han dirigido desde entonces tanto a la verificación del estado de catalogación e inventario como a sentar las bases para la detección de vulnerabilidades en la seguridad que puedan ser corregidas de la manera más temprana posible. Los resultados pretendidos son los siguientes:

- El establecimiento de un protocolo de colaboración que debe de ser suscrito por la Fiscalía Superior, la Iglesia católica y la Xunta de Galicia, que permita el seguimiento permanente de la evolución de la delincuencia contra este patrimonio. A modo de ejemplo, se ha detectado que, en función del momento, han sufrido sucesivos ataques los objetos tallados en piedra, los grandes objetos de bronce, campanas incluidas y finalmente piezas de plata.

- La elaboración por las fuerzas y cuerpos de seguridad del Estado de un manual de protección a difundir entre párrocos y parroquias de manera que permitan tanto el establecimiento de las medidas de seguridad más elementales como el conocimiento de la reacción más adecuada ante una sustracción, si ésta se produce. Este manual debe venir acompañado de planes formativos permanentes a los encargados de seguridad de este patrimonio.

En Andalucia, la Fiscalía Superior dictó un decreto de fecha 26 de diciembre de 2009 en relación con la necesaria erradicación de infracciones vinculadas al patrimonio histórico, particularmente en daños producidos por los grafitos sobre monumentos o edificaciones que hayan sido declarados bienes de interés cultural o que merezcan la misma protección provisional por haberse incoado el expediente correspondiente para llevar a cabo esta declaración. Como consecuencia, se hace una propuesta de actuaciones, entre las que destaca la elaboración de un protocolo de actuación, coordinación entre los diferentes cuerpos policiales, intensificar la coordinación entre las instituciones y los cuerpos policiales e instar a las diferentes administraciones públicas al control en el desarrollo de actividades que puedan resultar perjudiciales para la conservación de los BIC, tales como la concesión de licencias de restauración en espacios protegidos o entornos del BIC.

\section{Bibliografía}

GARCÍA CALDERÓN, J. M. (1999) Los daños por imprudencia al Patrimonio Histórico. Madrid: Centro de Estudios Jurídicos de la Administración de Justicia, 1999 